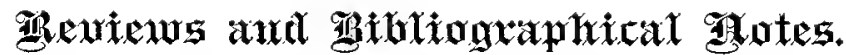

Operative Surgery of Brain. The Field and Limitation of the Operative Surgery of the Human Brain. By JoHn B. RoBERTS, A.M., M.D., Professor of Anatomy and Surgery in the Philadelphia Polyclinic, Surgeon to St. Mary's Hospital. Pp. 8o. P. Blakiston, Son, \& Co., Philadelphia.

This work is somewhat familiar to us, being the paper presented by Dr. Roberts to the American Surgical Association at its last meeting, elaborated and illustrated and arranged in a tasteful and pleasing manner. It would be interesting had we in the same binding the discussion which followed the reading of the paper. The membership of the Association comprises eminent gentlemen from various cities and those representing the different opinions on brain surgery. The discussion following the reading of any paper should equal, if not exceed, the value of the paper itself, provided each speaker refrains (which requires great self-control) from relating the minute history of his last private case allied in any possible manner to the subject under discussion, to the exclusion of his general experience and his belief in the general subject. However, the discussion on Dr. Roberts' paper can be found in the transactions of the Association if the reader is not convinced or converted by the paper itself. The book would be considered a radical one in almost any community, but in conservative Philadelphia, had its appearance not been anticipated and its author's views known, we fear that a few, at least, of the Quaker City surgeons would have succumbed immediately to attacks of apoplexy, a condition from which Dr. Roberts himself could not rescue them, apoplexy being one of the few pathological conditions not amenable to trephining.

After a short prelude, Dr. Roberts reaches his propositions, or his creed, as he asks to be permitted to call it. Brevity is one of the many commendable characteristics of the book. His propositions are as follows:

r. The complexus of symptoms called " compression of the brain " is due not so much to displacing-pressure exerted on the brain substance, as it is to some form or degree of intracranial inflammation. 
2. The conversion of a closed (simple) fracture of the cranium into an open (compound) fracture by incision of the scalp, is, with the improved method of treating wounds, attended with very little increased risk of life.

3. The removal of portions of the cranium by the trephine or other cutting instruments is, if properly done, attended with but little more risk to life than amputation of a finger through the metacarpal bone.

4. In the majority of cranial fractures the inner table is more extensively shattered than the outer table.

5. Perforation of the cranium is to be adopted as an exploratory measure almost as often as it is demanded for therapeutic reasons.

6. Drainage is more essential in wounds of the brain than in wounds of other structures.

7. Many regions of the cerebral hemisphres of man may be incised and excised with comparative impunity.

8. Accidental or operative injuries to the cerebral membranes, meningeal arteries, or venous sinuses, should be treated as are similar lesions of similar structures in other localities.

9. The results of the study of cerebral localization are more necessary to the conscientious surgeon than to the neurologist.

We take pleasure in endorsing each and every one of the above propositions, and feel confident that all the New York surgeons, excepting, perhaps, the very few who are too old, or their confrères who are worse than aged and unable to grasp new ideasthey who do not believe that true antiseptic surgery is superior to sepsis and suppuration; we believe that all except these will approve of Dr. Ruberts' conclusions. His experience has been our individual experience, and we think that every surgeon who can conscientiously say that he has treated every head and brain wound as antiseptically as the masters in that art direct, will endorse Dr. Roberts.

These propositions are considered individually at length by the author. They are short enough for. every one to read and too succinct to review or abstract. We would dwell a moment on the first, "the complexus of symptoms called 'compression of the brain,' is due not so much to displacing-pressure exerted on the brain substance, as it is to some form of intracranial inflammation," in the hope that some one may prove or disprove the assertion-the only theoretical one in the creed. Certain cases have caused us to question whether inflammation or inflammatory irritation can come on immediately after an injury and in amount sufficient to cause.complete paralysis. The paralysis follows the depression of bone almost immediately; too soon, it seems, to be due to any inflammatory process. Perhaps in cases where there is extensive depression of bone there is compression per se; in others it is due to inflammation.

A chapter on cerebral localization follows the argument of the propositions. It contains rules for trephining more minute than any heretofore published. 
The third and last chapter is devòted to the conditions demanding operative procedure, and with a few illustrative cases is very complete.

The general appearance of the book is excellent and a credit to the publishers.

F. C. F.

Psychiatry: A Clinical Treatise on Diseases of the ForeBrain, based upon a study of its structure, functions, and nutrition. By Theodore MeYnerT, M.D. Translated, under the authority of the author, by B. Sachs, M.D. Part I., The Anatomy, Physiology, and Chemistry of the Brain. New York, G. P. Putnam's Sons. I 885 .

\section{First Notice.}

The part of the original work of which this is in part a translation was reviewed in the October, I884, number of the JOURNAL of Nervous and Mental Disease. Meynert is perhaps the most involved of German-writing medical authors, and a translation of such an involved writer is a task of enormous magnitude. Putnam's translation of Meynert's "Brain of Mammals" was an ambitious attempt, which certainly was not a complete success by reason of its being made by an English-thinking person. The attempt, however, was worthy of all praise, since it introduced to English-speaking readers one of the great masters of cerebral anatomy. The translator of the present volume deserves great credit, apart from the merits of his translation, for a well-meant attempt to render Meynert more familiar to English-speaking medical men.

The translator, in his preface, says: "For the shortcomings of my translation I crave the indulgence of the reader. I am quite certain that those best acquainted with the original will not underrate the difficulties of the task and will be most lenient in passing judgment upon my errors." The present volume only includes that portion of the original first part which is devoted to the "Anatomy, Physiology, and Chemistry of the Brain"; the portions relating to prosencephalic diseases being reserved for a second part. That the present work of Meynert is entirely up to date cannot be said, since it bears, in many places, evidence that some of the work was written in $\mathbf{1} 875$, or even earlier; some in I 880 , and some between 1880 and the date of publication. A work so written can scarcely be homogeneous and this must of necessity add to the difficulties of the translator.

The preface gives a succinct digest of certain of Meynert's views, and therefore deserves quotation: "The reader will find no other definition of 'psychiatry' in this book but the one given on the title-page: "Clinical Treatise on Diseases of the Fore-Brain." It must be obvious that this translation is not clear, and would be liable to ridicule by a captious critic, similar to the ridicule heaped upon Dr. Mann's title: "Psychological Medicine and Allied Nervous Diseases." It would have been 